ТРУД И ОБРАЗОВАНИЕ: ОТ ОБЩЕСТВА ТРУДОВОГО К ЦИФРОВОМУ

(C) Четырова Любовь Борисовна - доктор философских наук, профессор, кафедра философии, Самарский национальный исследовательский университет имени академика С.П. Королева, 443086, Российская Федерация, г. Самара, Московское шоссе, 34.

E-mail: chetyrova@gmail.com. ORCID: https://orcid.org/0000-0001-5064-8735. Scopus ID: 57202548506, Web of Science: J-6298-2013

\begin{abstract}
АННОТАЦИЯ
Статья посвящена рассмотрению вопроса о том, как менялась взаимосвязь институтов труда и образования в европейской культуре, какие концептуализации труда и образования существовали в европейской философской и педагогической мысли. Показано, что труд и образование тесно связаны в своем историческом развитии, а идеи труда и образования, репрезентирующие эти культурные феномены, выражали эту связь различными способами в разные периоды развития европейской культуры. Сказано, что в греческой античности концептуализация труда заключалась в противопоставлении материального/производительного и созерцательного труда взращивания души и, соответственно, противопоставлении института труда и образования. Охарактеризовано, что Средневековье, сохраняя низкий статус материального/производительного труда, изменило вместе с тем смысл созерцательного труда, который наполнился религиозным содержанием. Обосновано, что в Новое время наряду с существующим институтом труда появился институт образования, составной частью которого стал институт профессионального образования. Дальнейшее развитие общества модерна привело к появлению так называемого «трудового общества», которое характеризовалось наличием глубинной связи между институтом труда и институтом образования. В «трудовом обществе» институт образования стал подготовкой к профессии. Выделены причины начавшихся на рубеже 60-х и 70-х годов прошлого века глубоких трансформаций в области труда, обозначенных метафорой «смерти труда». Показаны причины радикальных изменений феномена труда в потскапиталистическом и постсоциалистическом цифровом обществе, приведшие к разрыву непосредственной связи института труда и образования, а также дальнейшему расширению и росту дистанционного образования.
\end{abstract}

Ключевые слова: образование, высшее профессиональное образование, дистанционное образование, труд, трансформация труда, нематериальный труд, цифровое общество, посткапиталистическое общество.

Цитирование. Четырова Л.Б. Труд и образование: от общества трудового к цифровому // Вестник Самарского университета. История, педагогика, филология. 2018. Т. 24. № 4. С. 85-90. DOI: http:// doi.org/10.18287/2542-0445-2018-24-4-85-90.

This is an open access article distributed under the Creative Commons Attribution License Which permits unrestricted use, distribution, and reproduction in any medium, provided the original work is properly cited. (CC BY 4.0) 


\section{LABOR AND EDUCATION: FROM WORKING SOCIETY TO DIGITAL ONE}

(C) Chetyrova Lyubov Borisovna - Doctor of Philosophical Sciences, professor, Department of Philosophy, Samara National Research University, 34, Moskovskoye shosse, Samara, 443086, Russian Federation.

E-mail: chetyrova@gmail.com. ORCID: https://orcid.org/0000-0001-5064-8735. Scopus ID: 57202548506, Web of Science: J-6298-2013

\section{ABSTRACT}

The article discusses the problem of how the interrelation between the institutions of labor and education in European culture has changed. Also, the author analyses what kind of labor and education conceptualizations existed in European philosophical and pedagogical thoughts. She shows that labor and education are closely related in their historical development, and the ideas of labor and education, representing these cultural phenomena, expressed this connection in different ways in different periods of the European culture. According to her the Greek antiquity was characterized by opposing the institution of labor and education because the conceptualization of labor provided the opposition of the material/productive labor and contemplative one, which was cultivating the soul. During the Middle Ages, while maintaining the low status of material / productive labor, also changed the meaning of contemplative labor, which was filled with religious content. Author proves that in the New Age along with the existing labor institute an education institute appeared, which included the professional education institute. The further development of modern society led to the emergence of the so-called «work society», which was characterized by the deep connection between the institute of labor and of education one. The education institute was a preparation for the profession in the «work society» (U. Beck). Author highlighted the reasons of transformations in the field of labor that identified by the metaphor of the «death of work» in the 60-ies and 70-ies of the last century. Furthermore, the author shows the reasons of the radical changing the phenomenon of labor in the potscapitalist and postsocialist digital society. These reasons cause the rupture of the direct link between the institute of labor and education one, as well as the further expansion and growth of distance education.

Key words: education, higher education, distance education, labor, labor transformation, non-material labor, digital society, post-capitalist society.

Citation. Chetyrova L.B. Trud i obrazovanie: ot obshchestva trudovogo $k$ tsifrovomu [Labor and education: from working society to digital one]. Vestnik Samarskogo universiteta. Istoriia, pedagogika, filologiia [Vestnik of Samara University. History, pedagogics, philology], 2018, Vol. 24, no. 4, pp. 85-90. DOI: http:// doi.org/10.18287/2542-0445-2018-24-4-85-90.

\section{Введение}

Дискурс о труде и дискурс об образовании издавна являлись средствами выражения и легитимации социального неравенства и социальной селекции. В истории европейской культуры отношения институтов образования и труда устанавливались в зависимости от того, как осуществлялась концептуализация труда и какой ценностный статус в результате этого обретал производительный труд. Наблюдаемые сегодня глубинные трансформации в области труда, в результате которых доминирующим в общественном производстве становится не производительный, а нематериальный труд [Лазаротто 2008], не только меняют структуру профессий, но и существенно влияют на систему высшего профессионального образования. Уход многих профессий с рынка труда неминуемо ведет к невостребованности выпускников тех факультетов университетов, которые готовили студентов к этим профессиям. Иначе говоря, стремительно меняющийся институт труда с формирует запрос на определенные профессии, запрос, отвечая на кото- рый институт профессионального образования вообще и университетского в частности, чтобы быть успешным, должен меняться с той же стремительностью.

Целью данной статьи является анализ взаимосвязи институтов труда и образования в культуре в историческом аспекте, а также рассмотрение института высшего профессионального образования в контексте движения от трудового общества к цифровому.

\section{Становление институтов труда и образования}

В греческой античности сформулированный классиками античной философии идеал созерцательной жизни был вызван необходимостью разделения и противопоставления института образования и института труда. Раб, определяясь как говорящее орудие, лишался статуса человека и был инструментом, используемым свободнорожденным господином для осуществления созерцательной деятельности как цели и смысла его жизни. Необ- 
ходимой частью этой созерцательной жизни являлись занятия философией, и философское образование. Производительный труд приобретал в результате такой концептуализации низкий ценностный статус, вследствие того, что, во-первых, исполнялся рабом, во-вторых, был мотивирован потребностями тела, а не души. Те свободнорожденные, которые занимались производительным трудом, например, ремесленники и крестьяне, т. е. трудящиеся массы, приравнивались при таком подходе к рабам, так как их деятельность была обусловлена потребностями тела. И это при том, что они обладали статусом человека и гражданина.

В средневековом обществе монополия церкви на знание обрекала большинство мирян на неграмотность и невежество. Духовная и интеллектуальная элита общества была представлена главным образом сословием священнослужителей. Трудящиеся - крестьяне и ремесленники, исполнявшие производительный труд противостояли молящимся клирикам, владевшим монополией на образование.

В Новое время произошло кардинальное изменение соотношения институтов труда и образования, которые отныне тесно связаны между собой. Секуляризация культуры, в конечном итоге приведшая к ситуации «смерти Бога», когда трансцендентное стало имманентным, а человек заместил собою Бога и стал рассматривать себя как творца своего мира. По словам Ханны Арендт, утрата веры в потустороннее бессмертие заставила обратить взоры людей к самим себе [Арендт 2000, с. 336]. Благодаря обращению к самому себе, осмыслению своего назначения и роли в мире человек утвердился в том статусе, который прежде принадлежал Богу.

В этом контексте стали появляться философские и педагогические учения, которые обосновывали значимость производительного труда и высоко оценивали ремесла - проект Великого Восстановления наук Ф. Бэкона и педагогическое учение Я.А. Коменского. Проект Бэкона стал радикальной программой, направленной на создание условий для практические ориентированной науки, цель которой производить знания, необходимые человеку для установления своего господства над природой. Наука и труд становились формами власти человека над природой и миром. Бэкону принадлежит знаменитый лозунг «Знание - сила!», на многие века определивший ценностный статус науки и человека как «мастера своей судьбы» [Бэкон 1977, с. 464]. Для родоначальника эмпиризма практические искусства стоят выше чистой теории, так как именно производительный труд помогал в установлении и реализации власти над природой.

Бэконовские идеи легли в основу педагогического учения Коменского, его «пансофии». Особенностью пансофической школы Коменского было то, что она готовила учеников не только к познанию вещей, но осуществляла подготовку к труду. Он указывал на необходимость того, чтобы «ученики в этом месте обучения учились не для школы, а для жизни. И пусть отсюда выходят юноши деятельные, на все годные, искусные прилежные - такие, которым со временем можно будет без опасения доверить всякое житейское дело» [Коменский 1982 a, с. 47]. Главным принципом новой школы стал следующий: «тому, что должно делать, нельзя иначе научиться, чем делая это. Отсюда и изречение: работая, мы работаем и над самими собою. Писарь становится писарем лишь писанием, художник - рисованием, певец - пением» [Коменский 1982 b, с. 570].

В дальнейшем система классического образования, сложившаяся в обществе модерна, стремилась реализовать, восходящую к энциклопедизму гуманистов Возрождения, «пансофическую идею»: «ученик должен знать все обо всем». Данная система классического образования была представлена во множестве разнообразных образовательных практик и моделей образования.

В Новое время сформировалась «отраслевая культура», обусловленная прогрессирующим разделением труда в обществе. В «трудовом обществе» институт образования стал занимать подчиненное положение в отношении института труда: образование должно готовить человека к труду, к участию в производительной деятельности [Dahrendorf 1987, S. 176]. Модель профессиональной школы сложилась в эпоху расцвета «трудового общества», ее дидактические приемы были разработаны американским философом Д. Дьюи. Важным принципом разработанной им модели образования был приоритет интересов обучающегося как члена демократического общества. В основе концепции Д. Дьюи лежит идея о профессионально ориентированном обучении, что подразумевает доминирование прагматической ориентации на протяжении всего процесса обучения. Целью образования с точки зрения американского философа было формирование личности, способной интегрироваться в систему свободного предпринимательства.

Изменение характера и содержания труда в первой половине XX века оказали влияние, по его мнению, на статус профессий, непосредственно связанных с промышленностью, а также торговлей и всей сферы услуг. В индустриальную эпоху работа в промышленности приобрела большее интеллектуальное содержание и более широкие культурные возможности, чем когда-либо прежде, в связи с этим значительно возрос спрос на такое образование, которое ознакомило бы рабочих с научными и социальными достижениями [Дьюи 2000, c. 283-286].

Однако во второй половине $\mathrm{XX}$ века ситуация кардинально поменялась. С середины 60-х годов наметилась тенденция трансформации института труда, которую тут же обозначили броской метафорой «смерти труда». Трудовое общество, в котором труд был своего рода осью, общество, где образование было подготовкой профессии, досуг отдохновением от труда [Бек 2000, с. 262-263], стало меняться на глазах. необходимостью разъяснения того, что происходит с феноменом труда 
в современной культуре, чем вызвано изменение его места в иерархии ценностей человека постмодерного общества.

Философия отрефлексировала эту ситуацию в культуре и сделала это в разных направлениях. С точки зрения Ж. Бодрийяра, общественное производство стало замкнутой системой, занятой производством и воспроизводством труда. Бодрийяр осмыслил опыт студенческой революции мая 1968 года. Студенты вышли на улицы, так как осознали свою невостребованность и ненужность современному им производству. Бодрийяр зафиксировал ту точку, с которого началось изменение системы университетского образования под влиянием радикальных трансформаций общественного производства и труда [Бодрийяр 2000, с. 74].

Метафора «смерти труда» обозначила глубинные трансформации сферы промышленного производства и кризис модерного общества. Промышленный капитализм, заточив пролетария в заводские стены, тем самым четко обозначил границу между временем труда и свободным временем. Начиная с 80-х годов прошлого века работник стал осуществлять свои трудовые функции дистанционно, находясь дома (teleworking), что привело к размыву границы между временем труда и отдыха. Исследования, проведенные среди работников, практикующих teleworking, показали, что негативным здесь является уменьшение контроля над временем своего труда и его увеличение. Позитивным в этой форме труда является приобретение новых навыков и способностей и снятие различия между «женской» и «мужской» работой [Huws 1996, p. X]. Все это сопровождалось изменением смысла труда. Начавшийся процесс трансформации труда усугубили причины глобального характера - информатизация, кибернетизация, цифровизация культуры.

\section{Труд и образование в цифровую эпоху}

Тенденция сокращения сферы производительного/материального труда в цифровую эпоху обрела новые формы проявления. Роботизация, автоматизация и использование цифровых технологий в современном обществе радикально меняют как характер и содержание труда, так и структуру занятого в общественном производстве населения. Согласно отчету британских исследователей из Оксфордского университета (2016) в результате автоматизации под угрозой сокращения оказались $47 \%$ рабочих мест в США. При этом сокращение коснется не только работников низкоквалифицированного, но и высококвалифицированного труда в областях, далеких от производства. Например, крупнейшая компания Амазон, занимающаяся интернет-продажами, сегодня заменяет топ-менеджеров компьютерными программами, которые оказались более эффективными с точки зрения изучения предпочтений потребителей и формирования спроса на товары и услуги, предлагаемые компанией [Technology at work 2016]. Увеличение числа безработных ведет к пауперизации населения в высокотехнологичных обществах и появлению нового класса обездоленных - прекариата [Standing 2011, p. 1-31].

Цифровые технологии породили такой феномен как платформенный капитализм, возникший в результате появления онлайн-платформ, используя которые работник может осуществлять свои трудовые функции в режиме онлайн, а работодатель нанимать его [Srnicek 2017, p. 36-92]. Наряду с таким уже ставшим традиционным видом, как teleworking, возник, следовательно, новый вид работы вне стен офиса. Однако изощренность и степень эксплуатации работника в условиях платформенного капитализма значительно возрастают [Standing 2011, p. 140-141].

Кардинальные изменения труда в цифровом обществе оказывают сильное влияние на систему профессионального образования, так как ведут к сокращению числа студентов на специальностях, невостребованных на современном рынке труда. Как отмечает М. Маяцкий, в современной культуре все больше размываются границы между трудом и учебой, так как «образование через всю жизнь» вызвано постоянным рождением новых и умиранием старых профессий [Маяцкий 2015, с. 76].

Данные феномены указывают на глубинные трансформации, происходящие с трудом и профессиональным образованием и появление новых моделей труда и профессионального образования не только в посткапиталистическом, но и посткапиталистическом цифровом обществе.

Модели труда и профессионального образования в современнном российском обществе весьма разнообразны. Современная Россия в ракурсе трудовых практик являет собою чрезвычайно мозаичную картину. Разброс здесь чрезвычайно широк от практик когнитивного капитализма, процветающего в мегаполисах, до нео-архаических форм хозяйствования, обеспечивающих существование простых людей на перифериях, в особенности этнических. Соответственно, модели труда, идеи труда и работы, которыми руководствуются люди, являются весьма различны. Особый интерес представляют те модели и идеи труда, которыми руководствуются молодые люди. Если взрослые еще продолжают в какой-то мере воспроизводить ценности прежней эпохи и руководствоваться прежними идеями труда, то у поколения, родившегося в революционную эпоху рубежа 80-90-х годов, совсем иные ценности, в иерархии которых труд занимает далеко не высокие позиции.

Падение престижа труда в России вызвано не только экономическими условиями пореформенной России, где производство, а с ним и производительный труд понесли невосполнимые потери, но и теми тенденциями, которые свойственны цифровой экономике в целом.

С некоторым запозданием Россия переживает трансформацию из общества принуждения (к труду в том числе) к обществу соблазна (потребления). А это ведет к антропологическим изменени- 
ям, формированию нового образа человека от homo faber через homo ludens к какому человеку? Какую роль играет труд в этом движении и что происходит с его досугом? Если в обществе соблазна производство сместилось в область непроизводительную и превратило потребление в нематериальный труд [Лазаротто 2008], то культура Web 2.0 и неолиберализм породили дотоле невиданные виды труда. Речь идет, к примеру, о неоплачиваемом труде программистов-геймеров, добровольно участвующих в совершенствовании программного обеспечения игры, благотворительном труде, сетевом обмене дарами и т.п. К традиционным видам эксплуатации индивида в культуре Web 2.0 прибавилась эмоциональная и когнитивная эксплуатация просьюмеров [Бариле 2015, с. 155-157]. Появление новых видов труда и, соответственно, профессий меняет традиционно сложившуюся конфигурацию специальностей, подготовкой к которым занимаются вузы. А калейдоскоп рождающихся и умирающих в цифровом обществе профессий принуждает человека к профессиональному обучению через всю жизнь. Для работающего человека наиболее удобной формой является дистанционное образование, стремительно развивающееся в последнее время.

Современное общество отличают динамичность, непостоянство и взаимозависимость, которые сформировали особую культуру новой мобильности [ФИлиппов 2012]. Новая мобильность представляет собой не только перемещение людей в пространстве, перемещение товаров и предметов, но и виртуальные перемещения в Интернете, мысленные перемещения в кино, театре, ТВ, перемещения с помощью гаджетов. В условиях глобализации свободой пространственного перемещения обладает тот, кто продвинулся вверх по социальной лестнице [Филиппов 2012]. Именно новая мобильность стала еще одним фактором, способствующим распространению дистанционного образования. Данный тип профессионального образования выступает как самообразование человека мобильного, обретающего дополнительные степени свободы в своем образовании, снимающего ограничения модели классического образования.

\section{Заключение}

Подводя итоги, следует сказать, что труд и образование тесно связаны в своем историческом развитии, а идеи труда и образования, репрезентирующие эти культурные феномены, выражали эту связь различными способами и образами в разные периоды развития европейской культуры. В греческой античности концептуализация труда заключалась в противопоставлении материального/производительного и созерцательного труда взращивания души и, соответственно, противопоставлении института труда и образования. Средневековье, продолжая эту традицию, сохранило низкий статус материального/производительного труда, изменив вместе с тем смысл созерцательного тру- да, который наполнился религиозным содержанием. Новое время характеризуется появлением наряду с существующим институтом труда института образования, со временем породившем институт профессионального образования. Возникшее на определенном этапе развития общества модерна «трудовое общество» своей отличительной особенностью имело глубинную связь института труда и образования, ставшее подготовкой к профессии. Такая связь была разорвана в посткапиталистическом цифровом обществе, где образование претерпевает радикальные изменения.

\section{Библиографический список}

Арендт 2000 - Арендт $X$. Vita activa или о деятельной жизни / пер. с нем. и англ. В.В. Бибихина: монография. СПб.: Алетейя, 2000. 437 с.

Бариле 2015 - Бариле Н. Брендирование «я» в эпоху эмоционального капитализма. Эксплуатация «просьюмеров» от риторики double-bind к гегемонии исповеди // Логос. 2015. № 3 (105). C. 138-161. URL: http://logosjournal.ru/cgi-bin/authors.pl?author $=\%$ D $0 \% 91 \%$ D $0 \%$ B 0\% D $1 \% 80 \%$ D $0 \%$ B $8 \%$ D0\% B B \% D $0 \%$ B $5 \% 20 \%$ D $0 \% 9$ D $\%$ D $0 \%$ B $5 \%$ D $0 \%$ B B $\%$ $\mathrm{D} 0 \% \mathrm{BB} \% \mathrm{D} 0 \% \mathrm{BE} \&$ lang $=\mathrm{ru}$.

Бек $2000-$ Бек $\boldsymbol{У}$. Общество риска. На пути к другому модерну / пер. с нем.: монография. М.: ПрогрессТрадиция. 2000. 384 с

Бодрийяр 2000 - Бодрийяр Ж. Символический обмен и смерть / пер. с фр.: монография. М.: Добросвет, 2000. $387 \mathrm{c}$.

Бэкон 1977 - Бэкон Ф. Великое восстановление наук // соч.: в 2 т. 2-е испр. и доп. изд. Т. 1. М.: Мысль, 1977. С. $55-557$.

Дьюи 2000 - Дьюи Д. Демократия и образование: пер. с англ.: монография. М.: Педагогика-Пресс, 2000. $384 \mathrm{c}$.

Коменский 1982 a - Коменский Я.А. Пансофическая школа // Избранные педагогические произведения: в 2 т. Т. 2. М.: Педагогика, 1982. С. 44-98.

Коменский 1982 b - Коменский Я.А. Новейший метод языков. Х глава («Аналитическая дидактика») // Избранные педагогические произведения: в 2 т. Т. 1. М.: Педагогика, 1982. С. 528-597.

Лазаротто 2008 - Лазаротто М. Нематериальный труд // Художественный журнал. 2008. № 69. URL: http:// moscowartmagazine.com/issue/23/article/369.

Маяцкий 2015 - Маяцкий М. Освобождение от труда, безусловное пособие и глупая воля // Логос. 2015. № 3 (105). C. 72-87. URL: http://logosjournal.ru/arch/81/ 105_5.pdf.

Филиппов 2012 - Филиппов А. Парадоксальная мобильность // Отечественные записки. 2012. № 5(50). URL: http://magazines.russ.ru/oz/2012/5/2f.html.

Dahrendorf 1987 - Dahrendorf R. Fragmente eines neuen Liberalismus: monograph. Stuttgart: Dt. Verl. Anst.: 1987. $271 \mathrm{~S}$.

Huws 1996 - Huws U. Teleworking and gender: monograph. Brighton, UK, 1996. 84 p.

Srnicek 2017 - Srnicek N. Platform capitalism. monograph. Cambridge, UK: Polity Press, 2017. 170 p. 
Standing 2011 - Standing G. The Precariat. The New Dangerous Class: monograph. London, New York: Bloomsbury, 2011. 198 p.

Technology at work v2.0. The Future Is Not What It Used to Be. URL: https://www.citivelocity.com/citigps/ technology-work-v2-0.

\section{References}

Arendt 2000 - Arendt H. Vita activa ili o deiatel'noi zhizni. Per. s nem. i angl. V.V. Bibikhina: monografiia [Vita activa or on the active life. Translation from German and English by V.V. Bibikhin: monograph]. SPb.: Aleteiia, 2000, 437 p. [in Russian].

Barile 2015 - Barile N. Brendirovanie «ia» V epokhu emotsional'nogo kapitalizma. Ekspluatatsiia «pros'iumerov» ot ritoriki double-bind $\mathrm{k}$ gegemonii ispovedi [Branding «I» in the era of emotional capitalism. The exploitation of "prosumers» from double-bind rhetoric to the hegemony of confession]. Logos [The Logos Journal], 2015, no. 3 (105), pp. 138-161. Available at: http://logosjournal.ru/cgi-bin/ authors.pl?author $=\% \mathrm{D} 0 \% 91 \% \mathrm{D} 0 \% \mathrm{~B} 0 \% \mathrm{D} 1 \% 80 \% \mathrm{D} 0 \% \mathrm{~B} 8 \% \mathrm{D} 0 \%$ B B \% D 0\% B 5\% 20\% D 0\% 9D\% D0\% B 5\% D0\% B B \% $\mathrm{D} 0 \% \mathrm{BB} \% \mathrm{D} 0 \% \mathrm{BE} \&$ lang=ru [in Russian].

Beck 2000 - Beck U. Obshchestvo riska. Na puti $k$ drugomu modernu. Per. s nem.: monografiia [Risk Society: Towards a New Modernity: monograph]. M.: ProgressTraditsiia, 2000, 384 p. [in Russian].

Baudrillard 2000 - Baudrillard J. Simvolicheskii obmen i smert'. Per. s fr.: monografiia [Symbolic Exchange and Death: translation from French: monograph]. M.: Dobrosvet, 2000, 387 p. [in Russian].

Bacon 1977 - Bacon F. Velikoe vosstanovlenie nauk [Instauratio Magna]. In: Soch.: v 2 t. 2-e ispr. i dop. izd. T. 1. [Collected works: in two vol. $2^{\text {nd }}$ edition, revised and enlarged. Vol. 1]. M.: Mysl', 1977, pp. 55-557. [in Russian].
Dewey 2000 - Dewey J. Demokratiia i obrazovanie: Per. s angl.: monografiia [Democracy and education: Translation from English: monograph]. M.: PedagogikaPress, 2000, 384 p. [in Russian].

Comenius 1982 a - Comenius J.A. Pansoficheskaia shkola [School of Pansophy]. In: Izbrannye pedagogicheskie proizvedeniia: $v 2$ t. T. 2 [Collected works on education: in 2 vols. Vol. 2]. M.: Pedagogika, 1982, pp. 44-98 [in Russian]. Comenius $1982 \mathrm{~b}$ - Comenius J.A. Noveishii metod iazykov. X glava («Analiticheskaia didaktika») [The newest method of languages. Chapter X («Analytical didactics»)]. In: Izbrannye pedagogicheskie proizvedeniia: $v 2$ t. T. 1 [Collected works on education: in 2 vols. Vol. 1]. M.: Pedagogika, 1982, pp. 528-597 [in Russian].

Lazarotto 2008 - Lazarotto M. Nematerial'nyi trud [Non-material work]. Khudozhestvennyi zhurnal [Moscow Art Magazine], 2008, no. 69. Available at: http:// moscowartmagazine.com/issue/23/article/369 [in Russian].

Maiatsky 2015 - Maiatsky M. Osvobozhdenie ot truda, bezuslovnoe posobie i glupaia volia [Liberation from Work, Unconditional Income and Foolish Will]. Logos [The Logos Journal], 2015, no. 3(105), pp. 72-87. Available at: http:// logosjournal.ru/arch/81/105_5.pdf [in Russian].

Filippov 2012 - Filippov A. Paradoksal'naia mobil'nost' [Paradoxical mobility]. Otechestvennye zapiski, 2012, 5(50). Available at: http://magazines.russ.ru/oz/2012/5/2f.html [in Russian].

Dahrendorf 1987 - Dahrendorf R. Fragmente eines neuen Liberalismus: monograph. Stuttgart: Dt. Verl. Anst.: 1987, 271 p. [in German].

Huws 1996 - Huws U. Teleworking and gender: monograph. Brighton, UK, 1996, 84 p. [in English].

Srnicek 2017 - Srnicek N. Platform capitalism. monograph. Cambridge, UK: Polity Press, 2017, 170 p. [in English].

Standing 2011 - Standing G. The Precariat. The New Dangerous Class: monograph. London, New York: Bloomsbury, 2011, 198 p. [in English].

Technology at work v2.0. The Future Is Not What It Used to Be. Available at: https://www.citivelocity.com/ citigps/technology-work-v2-0 [in English]. 